\title{
A Comparative Study of Children from Multicultural and Rural Families: Sense of Self-Identity, Maternal Parenting Behavior and School Satisfaction
}

This study determines the factors that contribute to the sense of self-identity for children from multicultural and rural families and provides a systematic understanding of individual self-identity. It also provides implications on how parents, teachers, and professionals can approach their role when instructing and rearing children of different sociocultural backgrounds. The subjects consist of the 310 children from multicultural families (Korean fathers and immigrant mothers) residing in South Korea and 280 children from rural families with similar conditions to those in multicultural families in North Jeolla Province South Korea. The sense of self-identity and maternal parenting behavior were perceived differently by children of multicultural and rural families, whose sense of self-identity was affected by school satisfaction and maternal parenting behavior.

South Korean society is transforming from a homogeneous to a multicultural society. Immigrants have significantly increased through the expansion of personal exchanges. South Korea has to address the issue of living with immigrants. Such phenomenon of globalization drastically weakens the traditional

${ }^{*}$ Ph.D. Dept. of Child \& Family Studies, The Catholic University of Korea (hscho31@hanmail.net)

${ }^{* *}$ Corresponding author: Associate Professor, Dept. of Child \& Family Studies, The Catholic University of Korea (mhyukj@unitel.co.kr)

Key Words: multicultural children, rural children, self-identity, maternal parenting behavior, school satisfaction concepts of nation and sovereignty as well as diversifies society and culture. South Korea is no exception in the trend of multiculturalism (Hwang, 2008).

South Korea is not accustomed to immigration due to geographical and historical factors. "The single-nation country" should be a neutral concept. However, South Korea values the concept of racial homogeneity. This value of racial homogeneity lays the groundwork for the exclusionism of other people and cultures that leaves no room for relativistic cultural communication (Choe, 2008).

The national perception of South Korean has not yet matched its drastic social change. Society has just started to show phenomena that reflects the transformation into multiculturalism. One example is international marriages between Korean men and Southeast Asian women that began in the late 1980s and explosively increased in the 1990s (Han, 2006). International marriages have remarkably increased since 2003 due to the simplification of marriage procedures facilitated through the abolition of the South Korean-Chinese MOU and the expansion of international wedding brokers. Amounting to approximately twelve thousand (3.7\%) in 2000, international marriages rose to approximately thirty thousand (9.0\%) by about three times in 2011 (Statistics Korea, 2012). In rural areas, one third are internationally marriages. Given this trend, one in four children from primary schools will be from multicultural families. The statistics indicates that 
South Korean society is becoming a multiethnic and multicultural society. Subsequently, South Koreans are faced with new socioeconomic problems that involve communication, education and human rights. In addition, it is likely that the ratio of multicultural families will rapidly expand in South Korean society due to the low birth rate (Ministry of Health and Welfare, 2006).

Married couples often have difficulties in mutual adaptation due to differences in values, thinking and behavior. In addition, internationally married couples go through difficulties in adaptation because of language barriers and cultural background differences (Yang, 2006). The adaptation of multicultural children to South Korean society is an additional issue. In practice, most immigrant mothers bring up their children without adaptation to Korean language and culture. Nurtured by mothers with a foreign language and culture, children may show underachievement and an identity crisis (Oh, 2005).

Cohen (1982) argues that families formed by multiethnic marriages are not appropriate for the growth and development of children. The children from such a home feel lost between cultures contradictory in standards and values since they look exotic and are of unorthodox backgrounds (Garrod, Ward, Robinson, \& Kikenny, 1999; Williams, Nakashima, Kich, \& Daniel, 1996). This causes adolescents to ask themselves "which am I suited to?" and form a mental complex over social acceptance and the fear of rejection. Children are rejected by both majority and minority groups due to their uncertain identity (Lee \& Choi, 2008) and they tend to have more problems in identity, learning and behavior in the school environment (Herring, 1992; McRoy \& Freeman, 1986). Most of them experience an identity crisis while receiving a culturally mixed home education under the influence of mothers not accustomed to Korean language and culture or the Korean educational system (Oh, 2007).

The sense of self-identity begins with the family environment in early childhood. It is expanded and divided with structural integration along with the socialization from the interaction and identification with parents. More supportive parenting behavior results in a higher sense of self-identity in children (Park \& Lee, 2000) and the same sense of selfidentity is promoted through the relationships of parents and children in the family environment (Grotevant \& Cooper, 1985). According to Poston (1990), children from multicultural and multiethnic families develop a sense of self-identity different from those of single ethnic families, as they experience a guilty conscience and confusion and refuse to accept one aspect of cultural legacies from their biological parents under peer pressure.

In terms of parenting behavior, the authoritative attitudes of parents are closely related to the development of the children's sense of self-identity (Lee, 2002; Park \& Lee, 2000) and age appropriate control, warmth, love of parents are associated with an positive adolescent sense of self-identity (Bosma \& Gerrits, 1985; Richardson, Galambos, Schulenberg, \& Peterson, 1984).

For school-aged children, school has a great influence on building a sense of self-identity. Children expand their personal relations and explore their roles and identities in their interactions with teachers and peers. In addition, they develop their personality and character through the systematic socialization of learning activities. Children that have a higher sense of self-identity show a higher interest in learning activities (Lee \& Cheon, 2003) and the adaptation to school life. Primary school students build an emotional bond through peer relations. However, it is highly likely that they fail in their adaptation to school life if they are alienated from peers due to cultural diversity (Kim, 2008).

There are limited studies on Korean children from multicultural and rural families. In general, rural areas (differentiated from urban ones in demographic, economic and social terms) have higher levels of poverty and unemployment, while having low levels of education, per-capita income, and family income. The differences in education level become severe in rural and urban areas due to the population decrease of students that has resulted in the amalgamation of schools. Rural children have difficulties in their home environment as well. They receive less attention from parents who need to focus on earning an income to support their family and 
are unable to afford private educational institutions, supportive parenting guidance and close connection between home and school. In addition, most parents have problems, such as poverty, low education level, insufficient learning conditions, poor stimuli, low academic competitiveness and an excessive dependence on public education (Ministry of Education and Human Resources Development, 2008).

Rural children face many difficulties due to geographical conditions and insufficient educational stimuli. In particular, the home and school environment are inadequate for the needs of schoolaged children. Rural children often find it difficult to develop positive concepts of self-identity, since poverty deepens parental conflicts or discords. Even worse, divorce forces them to live with single parents or grandparents that cause emotional mal adjustments such as resentment, aggressiveness and depression. Especially, the children entrusted to grandparents have low levels of self-identity (Jung, 2007).

Accordingly, the present study investigated the relationships among children's sense of self-identity as an important factor to determine the success or failure in life, along with the maternal parenting behavior that represents the basic psychological home environment and the school satisfaction life of children.

There exist limited empirical studies on the possible comprehensive nature of the parental relationships of similarities and differences in parenting, satisfaction with school, and the sense of self-identity for children from multicultural and rural families. Significant research on the sense of self-identity has neglected to examine the comparative characteristics on the different factors that influence the sense of self- identity in multicultural families compared to those in rural families. A comparative approach provides insight into the sociocultural dimensions of parenting and child development and elucidates previously unexplored relationships. This study explores the different variables that contribute to the sense of self-identity between the two groups. This study seeks a systematic understanding of children's self-identity from multicultural and rural families and further offers practical implications for parents, teachers, and professionals whose sociocultural backgrounds is different.

This study had three major research questions.

1. Is there any difference in maternal parenting behavior and children's school satisfaction and the sense of self-identity between children from multicultural and rural families?

2. What is the relation of maternal parenting behavior and children's school satisfaction and sense of self-identity in the children from multicultural and rural families?

3. What extent does maternal parenting behavior and school satisfaction have on the children's sense of self-identity in multicultural and rural families?

\section{METHODS}

\section{Subjects}

Data for this study were obtained through a convenience sampling of 310 students with Korean fathers and immigrant mothers in the $4^{\text {th }}, 5^{\text {th }}$ and $6^{\text {th }}$ grades of primary schools in Jeollabuk-do South Korea. The children from $4^{\text {th }}$ to $6^{\text {th }}$ grades were selected as subjects because the sense of self-identity is not fixed and is able to continuously change with social realties (Kim, 1989). Multicultural realities are very different in metropolitan and provincial areas in terms of composition and environment. This study was limited to Jeollabuk-do because it encompasses immigrant mothers who identify themselves as Koreans and represent the families of the culturally heterogeneous in rural villages (Ministry of Health and Welfare, 2006).

Children in rural areas were sampled in primary schools in Jeollabuk-do. This study used the data of 280 students.

Table 1 illustrates the demographic features of the subjects. For multicultural family, a sampling was made of $1104^{\text {th }}$ grade $(35.5 \%), 905^{\text {th }}$ grade $(29.0 \%)$ and $1106^{\text {th }}$ grade (35.5\%) students and 157 male (50.6\%) and 153 female (49.4\%) students. In terms of maternal education level, 150 (48.4\%), 115 (37.1\%), $21(6.8 \%)$ and $24(7.7 \%)$ students had mothers who graduated from high school (or lower), 
Table 1. Sample Demographic Characteristics $(N=590)$

\begin{tabular}{|c|c|c|c|}
\hline & & $\begin{array}{l}\text { Children of multicultural family } \\
\qquad(\mathrm{n}=310)\end{array}$ & $\begin{array}{l}\text { Children of rural family } \\
\qquad(\mathrm{n}=280)\end{array}$ \\
\hline Grade & $\begin{array}{l}4^{\text {th }} \text {-grade } \\
5^{\text {th }} \text {-grade } \\
6^{\text {th }} \text {-grade }\end{array}$ & $\begin{array}{r}110(35.5) \\
90(29.0) \\
110(35.5)\end{array}$ & $\begin{array}{l}94(33.6) \\
94(33.6) \\
92(32.8)\end{array}$ \\
\hline Sex & $\begin{array}{l}\text { Boy } \\
\text { Girl }\end{array}$ & $\begin{array}{l}157(50.6) \\
153(49.4)\end{array}$ & $\begin{array}{l}144(51.4) \\
136(48.6)\end{array}$ \\
\hline Maternal education level & $\begin{array}{l}\text { High school or below } \\
\text { College } \\
\text { Graduate school or higher } \\
\text { No answer }\end{array}$ & $\begin{array}{c}150(48.4) \\
115(37.1) \\
21(6.8) \\
24(7.7)\end{array}$ & $\begin{array}{l}122(43.6) \\
106(37.9) \\
28(10.0) \\
24(8.6)\end{array}$ \\
\hline Paternal education level & $\begin{array}{l}\text { High school or below } \\
\text { College } \\
\text { Graduate school or above } \\
\text { No answer }\end{array}$ & $\begin{array}{c}223(71.9) \\
56(18.1) \\
10(3.2) \\
21(6.8)\end{array}$ & $\begin{array}{c}106(37.9) \\
124(44.3) \\
27(9.6) \\
23(8.2)\end{array}$ \\
\hline Maternal nationality & $\begin{array}{l}\text { China } \\
\text { Japan } \\
\text { Philippine } \\
\text { Other }\end{array}$ & $\begin{array}{c}102(32.9) \\
150(48.4) \\
45(14.5) \\
13(4.2)\end{array}$ & \\
\hline
\end{tabular}

college, graduate school (or higher), and gave no answer, In terms of paternal education level, 223 (71.9\%), 56 (18.1\%), $10(3.2 \%)$ and $21(6.8 \%)$ students had fathers who graduated from high school (or lower), college, graduate school (or higher), and gave no answer, respectively.

For rural families, the sampling was composed of $944^{\text {th }}$ grade $(33.6 \%), 945^{\text {th }}$ grade $(33.6 \%)$ and $926^{\text {th }}$ grade $(32.8 \%)$ students and 144 male $(51.4 \%)$ and 136 female (48.6\%) students. In terms of maternal education level, 122 (43.6\%), 106 (37.9\%), 28 (10.0\%) and $24(8.6 \%)$ students had mothers who graduated from high school (or lower), college, graduate school (or higher), and gave no answer, respectively. In terms of paternal education level, 106 (37.9\%), 124 (44.3\%), $27(9.6 \%)$ and $24(8.2 \%)$ students had fathers who graduated from high school (or lower), college, graduate school (or higher) and gave no answer, respectively.

\section{Measures}

Measures with no existing Korean translations were translated into Korean by the authors. To verify the accuracy of these translations, these transcripts were back coded into English and checked against the original transcript with inconsistencies resolved by a panel of experts.

Sense of Self-identity This study used a scale developed by Cho (2010) that verified the validity through the selection of 6 factor-specific questions with high load among those on Korean-Type Test of Sense of Self-Identity developed by Park (2003). A validity of .90 was obtained based on a total of 36 questions that include independence (6 items), selfreceptiveness ( 6 items), self-confidence in the future (6 items), goal-orientedness (6 items), leadership (6 items) and intimacy (6 items). The scale was scored on a 5-point Likert scale. Higher scores indicate higher levels of self-identity and the Cronbach's alpha was .88 .

Maternal Parenting Behavior The scale of Kim (2004) was used to measure the children's perceived maternal parenting behavior. The scale consisted of sub-categories, i.e. 10 items "warm/acceptance" (Cronbachs alpha .89), 10 items "rejecting/controlling" (Cronbach's alpha .83) and 10 items "permission/ indifference" (Cronbach's alpha .72) and was scored a 4-point Likert scale from "very different" (1 point) to "very similar" (4 points). Higher scores indicate how the child thinks his mother acts.

School Satisfaction To determine the children's school satisfaction, this study used a scale developed by Kang (2005) in consideration of South Korea's educational realities. The scale consisted of a total of 30 questions: learning activities (6 items), peer 
relations (6 items), relations with teachers (6 items), physical school environment (6 items) and school events \& special activities (6 items) and the Cronbach's alpha was .90. The scale was scored on a 5-point Likert scale. Higher scores indicate higher levels of school satisfaction.

\section{Procedures and Methods}

To examine the scales' difficulty and comprehensibility, preliminary surveys were conducted for 30 multicultural children in the $4^{\text {th }}, 5^{\text {th }}$ and $6^{\text {th }}$ grades of primary schools located in Seoul and Bucheon. No great problem was found in understanding the questions.

After preliminary surveys, investigators visited the schools in cooperation with the Jeollabuk-do Office of Education to collect 323 copies of the questionnaire from children of multicultural families and used 310 of them excluding those with missing answers. A questionnaire survey was conducted for rural children of primary schools in Jeollabuk-do. An analysis was made of 280 responses out of 310 that excluded ones with missing answers. The questionnaire copies were distributed to children of multicultural and rural families with the aid of school teachers after the study objectives were fully disclosed. Children who answered the questionnaire received two children's books for their participation and teachers were given small gifts for their assistance. Children were provided written consent forms for their participation and were asked to answer them on the spot.

For data analysis, this study calculated frequency, percentage, mean and standard deviation, t-test,
ANOVA, Scheffé post-test, Pearson's correlation, and regression analysis.

\section{RESULTS}

Differences in Maternal Parenting Behavior, Children's School Satisfaction and Sense of Self-identity

Table 2 shows the differences in maternal parenting behavior, children's school satisfaction and the sense of self-identity of children from multicultural and rural families.

T-tests showed the statistical significant differences in maternal parenting behavior. In terms of warm/ accepting $(t=-2.88, \mathrm{p}<.01)$, the children in rural families $(M=3.12, S D=.72)$ showed higher scores than those from multicultural families $(M=2.95$, $\mathrm{SD}=.68)$. In terms of permissive/indifferent $(t=2.52$, $p<.05)$ and rejecting/controlling $(t=3.09, p<.01)$, the children in rural families $(M=1.87, S D=.49 ; M=1.82$, $S D=.55)$ showed higher scores than the children from multicultural families $(M=1.77, S D=.62 ; M=$ 1.69, $S D=.41)$. The children from rural families perceived the warm/accepting to higher extent. However, the children from multicultural families perceived permissive/indifferent and rejecting/ controlling to higher extent.

There was a statistical significant difference in a children's sense of self-identity $(t=-3.72, p<.001)$. The children from rural families $(M=3.66, S D=.61)$ showed higher scores than those from multicultural one $(M=3.49, S D=.49)$. However, there was no difference between the groups in terms of children's school satisfaction.

Table 2. T-tests in Maternal Parenting Behavior, Children's School Satisfaction and Sense of Self-identity (N=590)

\begin{tabular}{llccc}
\hline \multirow{2}{*}{ Variables } & \multirow{2}{*}{ Group } & $\begin{array}{c}\text { Children of multicultural families } \\
(\mathrm{n}=310)\end{array}$ & $\begin{array}{c}\text { Children of rural families } \\
(\mathrm{n}=280)\end{array}$ & \multirow{2}{*}{$t$} \\
\cline { 3 - 4 } & & $M(S D)$ & $M(S D)$ & $-2.88^{* *}$ \\
\cline { 2 - 4 } & Warm/accepting & $2.95(.68)$ & $3.12(.72)$ & $2.52^{*}$ \\
Maternal parenting & Permission/indifferent & $1.87(.49)$ & $1.77(.62)$ & $3.09^{* *}$ \\
& Rejecting/controlling & $1.82(.55)$ & $1.69(.41)$ & 1.53 \\
School satisfaction & & $3.66(.58)$ & $3.58(.71)$ & $-3.72^{* * *}$ \\
Sense of self-identity & & $3.49(.49)$ & $3.66(.61)$ & \\
\hline
\end{tabular}

${ }^{*} p<.05,{ }^{* *} p<.01,{ }^{* * *} p<.001$ 
Relationships among Maternal Parenting Behavior, Children's School Satisfaction and Sense of Self-identity

Table shows the relationships among maternal parenting behavior, children's school satisfaction and sense of self-identity for children from multicultural and rural families.

For children from multicultural families, the sense of self-identity showed significant correlations with maternal parenting behavior, i.e. warm/ accepting $(r=.43, p<.001)$, permissive/indifferent $(r=-$ $.31, p<.001)$ and rejecting/controlling ( $r=-.47, p<$ $.001)$. In addition, there was a significant correlation $(r=.57, p<.001)$ between children's school satisfaction and sense of self-identity.

For children from rural families, the sense of self-identity showed significant correlations with maternal parenting behavior, i.e. warm/accepting $(r=.39, p<.001)$, permissive/indifferent $(r=-.39, p<$
$.001)$ and rejecting/controlling $(r=-.34, p<.001)$. In addition, there was a significant correlation between children's school satisfaction $(r=.49, p<.001)$ and the sense of self-identity.

Children from multicultural and rural families had higher sense of self-identity, when they perceive maternal parenting behavior to be more warm/ accepting and had a lower sense of self-identity when they perceive maternal parenting behavior to be more permissive/indifferent and rejecting/ controlling. Children from multicultural and rural families had a high sense of self-identity when they were satisfied with school.

Predictions of Maternal Parenting Behavior and Children's School Satisfaction on Children's Sense of Self-identity

VIF indexes were less than 10 , i.e. 1.07 to 1.38 , and show that there is no problem of multicollinearity.

Table 3. Zero-order correlations between variables $(N=590)$

\begin{tabular}{|c|c|c|c|c|c|}
\hline \multicolumn{2}{|c|}{ Children of rural families } & \multirow[b]{2}{*}{2} & \multirow[b]{2}{*}{3} & \multirow[b]{2}{*}{4} & \multirow[b]{2}{*}{5} \\
\hline $\begin{array}{l}\text { Children of multicultural } \\
\text { families }\end{array}$ & 1 & & & & \\
\hline 1. Warm/accepting & & $-.39^{* * * *}$ & -.06 & $.39^{* * * *}$ & $.39^{* * *}$ \\
\hline 2. Permission/indifferent & -.01 & & $.21^{* * *}$ & $-.27^{* * * *}$ & $-.39^{* * *}$ \\
\hline 3. Rejecting/controlling & $-.27^{* * * *}$ & $.40^{* * * *}$ & & $-.23^{* * *}$ & $-.34^{* * *}$ \\
\hline 4. School satisfaction & $.46^{* * * *}$ & $-.15^{* *}$ & $-.26^{* * *}$ & & $.49^{* * *}$ \\
\hline 5. Sense of self-identity & $.43^{* * *}$ & $-.31^{* * * *}$ & $-.47^{* * * *}$ & $.57^{* * *}$ & \\
\hline
\end{tabular}

Table 4. Regression of Maternal Parenting Behaviors and Children's Satisfaction with School on Children's Sense of Selfidentity $(N=590)$

\begin{tabular}{|c|c|c|c|c|c|}
\hline & & \multicolumn{4}{|c|}{ Sense of self-identity } \\
\hline & & \multicolumn{2}{|c|}{$\begin{array}{l}\text { Children of multicultural families } \\
\qquad(\mathrm{n}=310)\end{array}$} & \multicolumn{2}{|c|}{$\begin{array}{l}\text { Children of rural families } \\
\qquad(\mathrm{n}=280)\end{array}$} \\
\hline & & B & $\beta$ & B & $\beta$ \\
\hline \multirow{3}{*}{$\begin{array}{l}\text { Maternal parenting } \\
\text { behavior }\end{array}$} & Warm/accepting & .12 & $.17^{* * * *}$ & .16 & $.19^{* * *}$ \\
\hline & Permission/indifferent & -.15 & $-.15^{* * *}$ & -.18 & $-.19^{* * *}$ \\
\hline & Rejecting/controlling & -.23 & $-.26^{* * *}$ & -.33 & $-.22^{* * * *}$ \\
\hline School satisfaction & & .34 & $.40^{* * * * *}$ & .27 & $.32^{* * * *}$ \\
\hline$F$ & & $68.24^{* * * *}$ & & $27.99^{* * *}$ & \\
\hline$R^{2}$ & & .47 & & .38 & \\
\hline$A d j-R^{2}$ & & .47 & & .37 & \\
\hline DW & & 2.12 & & 1.85 & \\
\hline
\end{tabular}

$p<.001$ 
Durbin-Watson coefficients (1.85 to 2.12$)$ satisfy the basic hypothesis for regression analysis.

For the sense of self-identity of children from multicultural families, significant factors are the subcategories of maternal parenting behavior, i.e. warm/ accepting $(\beta=.17, \quad p<.001)$, permissive/indifferent $(\beta=-.15, p<.001)$ and rejecting/controlling $(\beta=-.26$, $p<.001)$. Another significant factor is the children's school satisfaction $(\beta=.40, p<.001)$ and this produced a model that explained $47 \%$ of the regression $\left(\operatorname{Adj} R^{2}\right)$.

For the sense of self-identity of the children from rural families, significant factors are the subcategories of maternal parenting behavior, i.e. warm/ accepting $(\beta=.19, \quad p<.001)$, permissive/indifferent $(\beta=-.19, p<.001)$ and rejecting/controlling $(\beta=-.22$, $p<.001)$. Another significant factor is school satisfaction life $(\beta=.32, p<.001)$ and this produced a model that explained $37 \%$ of the regression $\left(\operatorname{Adj} R^{2}\right)$.

Children's school satisfaction and rejecting/ controlling among maternal parenting behavior were the factors that had the greatest influences on the children's sense of self-identity from multicultural and rural families.

\section{DISCUSSIONS}

This study promotes an understanding of children from multicultural and rural families by exploring maternal parenting behavior and children's school satisfaction as variables that affect their sense of selfidentity. The discussion focuses on the findings of the research questions.

\section{Differences in Maternal Parenting behavior and Chil- dren's School Satisfaction and Sense of Self-identity}

First, there were significant differences in maternal parenting behavior between children from multicultural and rural families. The children from rural families perceived the warm/accepting to a higher extent versus children from multicultural families that perceived permissive/indifferent and rejecting/ controlling to a higher extent. The determination of why children from rural families perceived the warm/accepting to higher extent rather than children from multicultural families is beyond the scope of this analysis. One possible explanation for this finding is that parents might have different belief systems about the parenting of children. For instance, severely stressed by international migration accompanied by cultural differences, immigrants often show the parenting behavior such as permissive, indifferent, rejecting and controlling. Kwak (2008) reports that multicultural family mothers are more depressed, pessimistic and stressed by parenting than normal family one. In addition, they show more passive and indifferent parenting attitude, provide less appropriate guidance and stimuli as well as impose their expectations coercively rather than respect the autonomy of children. One implication of this finding is that multicultural families need greater assistance for effective methods to facilitate parent-child-relationships and raise children under multicultural family conditions. Subsequently, it is necessary to conduct a systematic parents training program for mothers of multicultural families on a regular basis.

Second, there was no significant difference in the school satisfaction for children from multicultural and rural families. This is because areas of rural children are faced with more difficulties than urban ones due to geographical characteristics and insufficient stimuli. However, it should be noted that the children of multicultural families can experience severe psychological and sociocultural difficulties when they enter a new culture (Ward \& Kennedy, 1994) because school age children are negatively affected by poor family structure and circumstantial environments (Yang \& Yoo, 2003). Future research required to determine if the factors that affect children's school satisfaction are different in regard to the types of family.

Third, there were significant differences in the self-identity of the children from multicutural and rural families. A higher sense of self-identity was shown by children of rural families compared to children of multicultural families. This supports the study by Kim (2010) that the children of multicultural families had a significantly lower sense of self-identity than homogeneous families because internationally married women select immigration for socioeconomic reasons. However, it is looked down 
on for the reason of the low economic levels of her fatherland that results in unequal relations within a family and a negative influence on children. The children of multicultural families experience confusion in self-acceptance that causes a critical self-assessment and low sense of self-identity (Wigfield, Eccles, Maciver, Reuman, \& Midgley, 1991). It is important for professionals to note that children from multicultural families require special attention to take advantage of the opportunity for a high sense of self-identity. Professionals are advised to identify the adverse outcomes of a low sense of self-identity and develop effective ways to deal with negative outcomes for children in multicultural families.

\section{Relationships of Maternal Parenting Behavior and Children's School Satisfaction and Sense of Self-identity}

Maternal parenting behavior and a children's sense of self-identity are in a positive correlation with warm/accepting behavior, however, in a negative correlation with permissive/indifferent and rejecting/ controlling behavior. This shows that the psychological environment of family is associated with the constitution of children's sense of self-identity. It also supports previous studies (Lee, 1995; Richardson, Galambos, Schulenberg, \& Peterson, 1984) that show maternal behavior authoritative parenting attitudes are in a positive correlation with an adolescent sense of self-identity. These are in the same context as the study by Pable (1965) that too strict control prevents children from building a positive sense of selfidentity.

Children's sense of self-identity and school satisfaction are in a positive correlation. This is in the same context as the study by Moon (2001) in that the children with higher self-efficacy are more satisfied with school and the study by Rutter (1985) shows that relations with teachers and friends are closely related to the children's sense of self-identity.

Maternal parenting behavior and children's school satisfaction are in a positive correlation with warm/accepting behavior, however, in negative correlations with permissive/indifferent and rejecting/ controlling behavior. This supports the study by Byun (2005) that children are more satisfied with school when maternal parenting behavior is affective, receptive, democratic and authoritative. In terms of the psychological environment of the family, excessive love and concern have negative influences on school and children from families filled with love are well adjusted to learning activities, teachers, friends and school life (Park, 1995). The school life of children is affected by parental values and the interest in education as well as the structural deficiency of home (Kim, 2003).

This highlights the necessity of a longitudinal study in depth. A longitudinal study can show whether there are critical periods in which maternal parenting behavior and school satisfaction are particularly likely to affect the sense of self-identity for children from multicultural and rural families.

Predictions of Maternal Parenting Behavior and Children's School Satisfaction on Children's Sense of Self-identity

The sense of self-identity of children is significantly affected by the school satisfaction that includes the relations with peers and teachers. At a time of transition into an adolescent age, children are more sensitive to peers or teachers who influence their sense of self-identity and evolve into society through the school environment (Yang, 1999). The reason why the role of a teacher is so critical is because a teacher's interest and attention influences children's aspiration for learning and positive peer relationships (Yoon, 2005).

Maternal parenting behavior has a significant influence on children's sense of self-identity and supports the study by Felner et al. (1982) where maternal parenting behavior plays an important role in the self-concepts of children. Especially, immigration is not easy for young women and their belief in international marriage seems to have great influence on their children.

All of the factors associated with a sense of selfidentity examined in this study are equally important for children from multicultural and rural families. It is likely that the quality of parenting and school satisfaction that the children perceive has an enormous impact on children's sense of self-identity.

There are limitations to this study that should be considered in future related research. First, this study 
addressed primary school children from multicultural and rural families in Jeollabuk-do, Korea and a broader study is needed to generalize the results. Second, the present study looked into maternal parenting behavior and school satisfaction to determine their influences on the children's sense of self-identity. However, future research is needed to identify additional factors within as well as beyond the family and school system that can more completely explain the sense of self-identity for children from multicultural and rural families. Third, the data collected through the questionnaires was all self-reported and their accuracy cannot be validated. Subsequently, more multilateral results that include parent and teacher questionnaires would provide multiple perspectives on the development of children from multicultural and rural families.

Despite these limitations, the present study is significant in that it provides concrete and clear guidance to parents, educators, and policy makers to improve children's sense of self-identity. It also highlights the growing importance to develop and manage a sense of self-identity improvement programs suitable for children from multicultural and rural families.

\section{REFERENCES}

Bosma, H. A., \& Gerrits, R. S. (1985). Family functioning and identity status in adolescence. Journal of Early Adolescence, 5(1), 69-80.

Byun, M. S. (2005). Elementary students' perception on the relation between parents' rearing attitudes and children's adjustment to school life. Master's thesis, Wonkwang University, Jeonbuk.

Cho, H. S. (2010). A sense of self-identity in elementary school children of multicultural families: In respect to the relations between maternal mother's behaviors and children's satisfaction levels with school. Doctoral dissertation, The Catholic University of Korea, Seoul.

Choe, J. S. (2008). Task of substantialization of teaching Korean in the multi-cultural era. The Korean
Society of Bilingualism, 37, 287-316.

Cohen, N. (1982). Same or different? A problem of identity in cross-cultural marriage. Journal of Family Therapy, 4, 177-199.

Felner, R. D., Ginter, M. A., \& Primavera, J. (1982). Primary prevention during school transitions: Social support and environmental structure. American Journal of Community Psychology, 10, 277-290.

Garrod, A., Ward, J. V., Robinson, T. L., \& Kikenny, R. (1999). Souls looking back: Life stories of growing up back. New York: Routledge.

Grotevant, H. D., \& Cooper, C. (1985). Patterns of interaction in family relationships and the development of identity formation in adolescence. Child Development, 56, 415-428.

Han, G. S. (2006). Family life and cultural encounter of foreign wives in rural area. Korean Society for Cultural Anthropology, 39(1), 198-243.

Herring, R. D. (1992). Biracial children: An increasing concern for elementary and middle-school counselors. Elementary School Guidance and Counseling, 27, 123-130.

Hwang, B. J. (2008). A study on educational policy for multicultural family children. Doctoral dissertation, Anyang University, Gyeonggi.

Jung, Y. J. (2007). Family characteristics and school adjustment of the children of marriage migrantfamilies. Master's thesis, The Catholic University of Korea, Seoul.

Kang, Y. J. (2005). The developing the inventory of the level of children's school life satisfaction survey in elementary school. The Journal of Elementary Education, 12(2), 187-204.

Kim, G. J. (2008). Psychological problems and school adjustment of the children of multicultural family. Master's thesis, Jinju National University, Jinju.

Kim, H. J. (2003). Effecting adolescents school adjustment from the low-income family. Master's thesis, Dongduk Women's University, Seoul.

Kim, H. T. (1989). A study of the development and the measurement of ego-identity in Korean youth. Doctoral dissertation, Chungnam National University, Daejeoun. 
Kim, M. J. (2004). The relations between children's perception of parental childrearing behaviors and their behavior problems. Master's thesis, Yonsei University, Seoul.

Kim, S. I. (2010). Comparison of psychological features between children in multicultural families and children in general families regarding adaptation to school life. Master's thesis, Ewha Womans University, Seoul.

Kwak, K. J. (2008). Development and adaptation of children from multicultural families. Symposium of Korean Psychological Association, 1-26.

Lee, H. R., \& Cheon, M. S. (2003). Relationship analyses between adolescents' ego-identity and school life adjustments. Korean Journal of Youth Studies, 10(4), 511-541.

Lee, K. Y. (2002). Ego-identity of school-aged children: Effects of level of income and perceived parental behaviors. Journal of the Korean Home Economics Association, 40(10), 65-76.

Lee, S. G. (1995). The relationship between ego-identity and adolescent's perception of parent's rearing attitudes. Master's thesis, Keimyung University, Daegu.

Lee, S. H., \& Choi, W. S. (2008). A study on the cultural identity and social relationships of children in an international marriage family. Korean Journal of Family Welfare, 13(3), 163-185.

McRoy, R. G., \& Freeman, E. (1986). Racial identity issues among mixed-race children. Social Work in Education, 8, 164-174.

Ministry of Education and Human Resources Development (2008). Korean child and adolescent development report. Ministry of Education and Human Resources Development, Korea.

Ministry of Health and Welfare (2006). Analysis of immigrant marriage in Korea. Ministry of Health \& Welfare, Korea.

Moon, M. A. (2001). The relation of self concept, selfefficacy and school related achievement. Master's thesis, Hongik University, Seoul.

Oh, K. S. (2007). Multiculturalism in South Korea: A critical review. Hanwool.
Oh, S. B. (2005). A case study on the growing of Kosian children and its social environment. Journal of Korean Education, 32(3), 61-83.

Pable, M. W. (1965). Some parental determinants of ego identity in adolescent boys. Dissertation Abstracts International, 26, 3480-3481.

Park, A. C. (2003). Validation of Korean adolescent ego-identity scale. The Korea Journal of Psychology, 17(3), 373-393.

Park A. C., \& Lee, S. K. (2000). A structural analysis of ecological variables affecting adolescent ego-identity development centered on sex and age. The Journal of Education Research, 20(2), 255-282.

Park, S. H. (1995). Home environment of elementary school children and the relationship between school adjustment and satisfaction. Master's thesis, Konkuk University, Seoul.

Poston, W. (1990). The biracial identity development model: A needed addition. Journal of Counseling and Development, 69, 152-155.

Richardson, R., Galambos, N, M., Schulenberg, J., \& Peterson, A. (1984). Young adolescents' perception of the family environment. Journal of Early Adolescence, 5, 131-153.

Rutter, M. (1985). Studies of psychosocial risk: The power of longitudinal data. Cambridge: Cambridge University Press.

Statistics Korea (2012). Statistic Korea.

Ward, C., \& Kennedy, A. (1994). Acculturation strategies, psychological adjustment and sociocultural competence during cross-cultural transitions. International Journal of Relations, 18(3), 329-343.

Wigfield, A., Eccles, J. S., Maciver, D., Reuman, D. A., \& Midgley, C. (1991). Transitions during early adolescence: Changes in children's domain-specific selfperceptions and general self-esteem across the transition to junior high school. Developmental Psychology, 27, 552-565.

Williams, T. K., Nakashima, C. L., Kich, G. K., \& Daniel, G. R. (1996). Being different together in the university classroom: Multiracial identity as transgressive education. In M. P. Root (Ed.), The multiracial experience: Racial borders as the new frontier. 
Thousand Oaks, CA: Sage.

Yang, S. M. (2006). Adjustment and an aspect of family life of the rural international marriage coupleFocusing on the Chinese (Korea tribe), Japanese, and Philippine immigrant woman and their husband. The Korean Rural Sociological Society, 16(2), 151-179.

Yang, W. K. (1999). The Relations between peer acceptance and peer victimization and self-esteem in adolescents. Master's thesis, Ewha Womans University, Seoul.

Yang, S. M., \& Yoo, Y. J. (2003). Effects of self-esteem, healthiness of family, and sociodemographic variables on the school life adjustment in rural adolescents. Journal of the Korean Home Economics Association, 41(9), 121-134.

Yoon, G. S. (2005). Relationship between student's perception of teacher's behaviors and the student's satisfaction level in their school lives. Master's thesis, Suncheon University, Jeonnam.

Received October 10, 2012

Revised December 05, 2012

Accepted December 07,2012 